\title{
The Cost Management of Innovative Products in an Industrial Enterprise Given the Risks in the Digital Economy
}

\author{
Ekaterina Burova $^{1 *}$, Sergey Grishunin ${ }^{2}$, Svetlana Suloeva ${ }^{1}$, Andrei Stepanchuk ${ }^{1}$ \\ ${ }^{1}$ Peter the Great St. Petersburg Polytechnic University, 29 Politechnicheskaya Ulitsa, St. Petersburg, 195251, \\ Russia \\ ${ }^{2}$ National Research University, Higher School of Economics, 20 Myasnitskaya Ulitsa, Moscow, 101000, Russia
}

\begin{abstract}
This study aims to develop a mechanism for the cost management of innovative products in an industrial enterprise given the inherent risks. Under the conditions of the high volatility of the digital economy, risk assessment in cost management, as well as the development of some mechanisms for staying flexible and adaptable with regard to continual changes, is a priority for the further development of cost management systems for an industrial enterprise. The research results include: (1) a mechanism for assessing and considering the changes in the key cost drivers, which continuously controls the target cost level that has been achieved and can be used for taking into account the risk factors in cost management and for increasing the effectiveness of the business processes of industrial enterprises operating in the digital economy; and (2) a description of the methods recommended for implementing each stage of the mechanism suggested. The mechanism is based on the synthesis of the cost driver concept and the risk-controlling concept. The following tools were used to develop the mechanism: target-costing, kaizen-costing, variance analysis for cost planning, accounting and analysis, an Ishikawa diagram, a fault tree for identifying risk factors for key cost drivers, and simulation modeling using the Monte Carlo method. The mechanism: (1) makes it possible to consider the high uncertainty level of the external environment and the effect of risks in the cost management system; (2) can be used to control the level of target costs reached in real time and introduce prompt corrections regarding the planned costs according to external and internal changes; and (3) is based on using modern, high-precision tools for assessing risks and the effect they produce on the costs and profitability of an industrial enterprise. The advantages above help to increase the dynamics and flexibility of the process of the cost management of innovative products and to maintain such products' competitiveness.
\end{abstract}

Keywords: Cost management; Digital economy; Innovative products; Key cost drivers; Key risk factors

\section{Introduction}

Studies conducted by specialists in national industrial enterprises reveal that its cost management system is one of the top priorities for the digital development of an enterprise ( $\mathrm{Su}$ and $\mathrm{Wu}, 2019$; Mizikovskii, 2020). Being a subsystem of corporate management, cost management is considered "in the information-tool environment of enterprise management as a powerful driver of transformation processes, which ensures that digital systems and technologies are introduced" (Mizikovskii, 2020). 
The digital economy provides vast opportunities for the continuous improvement of the processes, technologies, and competences of management accounting, which helps to considerably increase the efficiency of cost management in an industrial enterprise (Bencsik, 2020; Bhimani, 2020). The tools of the digital economy, such as big data, machine learning, blockchain, and cloud computing, can be used in a cost management system to improve the accuracy of information and decision-making and to respond effectively to changes in the external and internal environment of an enterprise, thus making business processes more efficient (Berawi, 2020). According to the results of the global research study in the field of cost management conducted by Deloitte every other year, in 2019, the top priorities in terms of the strategic goals of industrial enterprises were sales growth, technology implementation, product profitability, digital enablement, and cost reduction 1 . According to the study, $78 \%$ of the respondent industrial companies failed to achieve the cost-cutting values they had planned, $15 \%$ reached their target values, and just $7 \%$ exceeded them. Cost-cutting value targets are mostly not achieved due to the occurrence of numerous risks in the turbulent surroundings of an industrial enterprise, which prevent such a company from reaching its objectives. Considering risks within cost management systems and developing mechanisms for flexible adaptation to ongoing changes are vital to the further improvement of cost management systems. Today digital transformation is especially important in managing the costs of innovative products (IP) (Mizikovskii, 2020). In order to manufacture competitive products and to guarantee that the value of an industrial enterprise will grow, it is not enough to just determine the "target" costs of IP. There is the need for a mechanism that can be used to achieve the target values of costs given the continuous effects of externalities and internalities on the activities of an enterprise. This study aims to develop a mechanism for managing the costs of IP faced by an industrial enterprise given the risks. In order to reach this goal, the following objectives have to be attained: (1) study the modern concepts that are used to manage the costs of IP and analyze the existing risk management concepts; (2) suggest a stage-by-stage mechanism for accounting for risks in the cost management of IP; and (3) choose and substantiate the methods and tools necessary for the implementation of each stage of the mechanism. The mechanism relies on the interaction between a cost management system and a risk management system and implies using the main principles of cost drivers, risk controlling, variance analysis, target-costing, and kaizen-costing. This mechanism can be used to control the target cost values reached in real time and to take corrective actions in the case of any deviation.

The review of the literature dedicated to managing the costs of IP shows that a large variety of methods are suggested (Wang et al., 2020). Today, methods such as target-costing and kaizen-costing are recommended (Olszewska, 2019) because they embrace the client focus and customization of an enterprise (Daneci-Patrau and Coca, 2017), and at the same time, they make the company strive for a cost level lower than that of its competitors. If target-costing and kaizen-costing methods are used, an enterprise can set correct objectives in terms of cost assessment and find ways to achieve them. However, the above methods are not used to consider the risks that may arise due to the continuous interaction of an enterprise with the external environment, which makes them less efficient. The concept of cost drivers was designed for the profound analysis of costs and the factors that generate them in order to increase the quality and efficiency of cost management. Yet, such analysis does not make it possible to monitor the changing cost drivers that arise from the transformation of the enterprise's external environment, which makes the concept static. Variance analysis, based on its classical interpretation, is a method of retrospective analysis, which is used by industrial enterprises for evaluating and analyzing the actual 
deviations in different cost drivers. This work suggests using the main principles of variance analysis to protect an enterprise from and account for the deviations in key cost drivers from the target cost values, related to possible risk occurrence. The academic literature review (Samimi, 2020; Grishunin et al., 2020) illustrates that the modern tools of risk management described above consider the specifics regarding the operation of industrial enterprises in the digital economy, but that there are not enough research studies in the field of risk management and cost management integration.

\section{Methods}

In terms of theory and methodology, the study relies on the works of foreign and Russian researchers in the fields of cost management and risk management. Based on the synthesis of the concepts of cost drivers and risk controlling, the paper suggests a mechanism for assessing and accounting for changes in the key cost drivers and which, therefore, continuously controls the target cost values. It helps to consider risk factors in cost management and increase the effectiveness of business processes of industrial enterprises operating in the digital economy.

The concept of cost drivers suggests that in order to manage costs effectively, attention must be paid not only to the costs themselves, but also to the factors that drive them. For modern enterprises operating in an unstable environment, the concept of cost drivers is extremely important. It is used in cost management tools, such as activity-based costing, standard-costing, cost drivers analysis (CDA), and value engineering (Banker et al., 2018). The concept of risk controlling is a target-oriented integrated risk management system for controlling risk in the processes of planning, analysis and assessment, control and accounting, and production and regulation, including project activities. In innovation activities related to the manufacture and sales of products, risk controlling aims to reduce the risk that the enterprise will fail to achieve its goals (for example, the target profitability of the IP) (Grishunin et al., 2020). The following tools are used: (1) a cost management system, supporting the cost-cutting strategy, implementing the functions of the planned manufacturing of new products and preventive cost control, and determining the target cost according to the market conditions - target costing (Ahn et al., 2018); (2) a system for finding ways to gradually cut costs and achieve the target costs and the profitability of production - kaizen-costing (Olszewska, 2019); (3) variance analysis and CDA, which can be used to determine the change in the self-cost of IP as a result of the effects of various factors (Matsuoka, 2018); (4) an Ishikawa diagram and a fault tree for identifying the risk factors for key cost drivers (Grishunin et al., 2020); and (5) simulation modeling using the Monte-Carlo method. This method is based on the value at risk (VAR) approach used in financial management (Grishunin et al., 2020).

\section{Results and Discussion}

The mechanism can be used for measuring the effects of uncertainties and risks in the external and internal environment on the key cost drivers (KCD) of IP of any type and to control the achievement of the target values of costs to ensure the profitability of the products. Figure 1 presents an algorithm of the cost management mechanism given the risks.

During the first stage of the mechanism, the target cost (TC) is determined by the target costing of the IP, and a list of cost drivers is formed for the business processes of the industrial enterprise. It is recommended to form the list of cost drivers using one of the concepts of cost drivers suggested by Porter (2005), Shank and Govindarajan (1993), and 
Donelan and Kaplan (1998). These concepts are different from the traditional ones in that they can be used to identify the cost drivers in the value chain. The methods for deciding on cost factors are as follows: the analysis of the company's previous experience, an expert method, SNW-analysis, regression and correlation analysis methods, and competitive cost analysis (Grishunin et al., 2020).

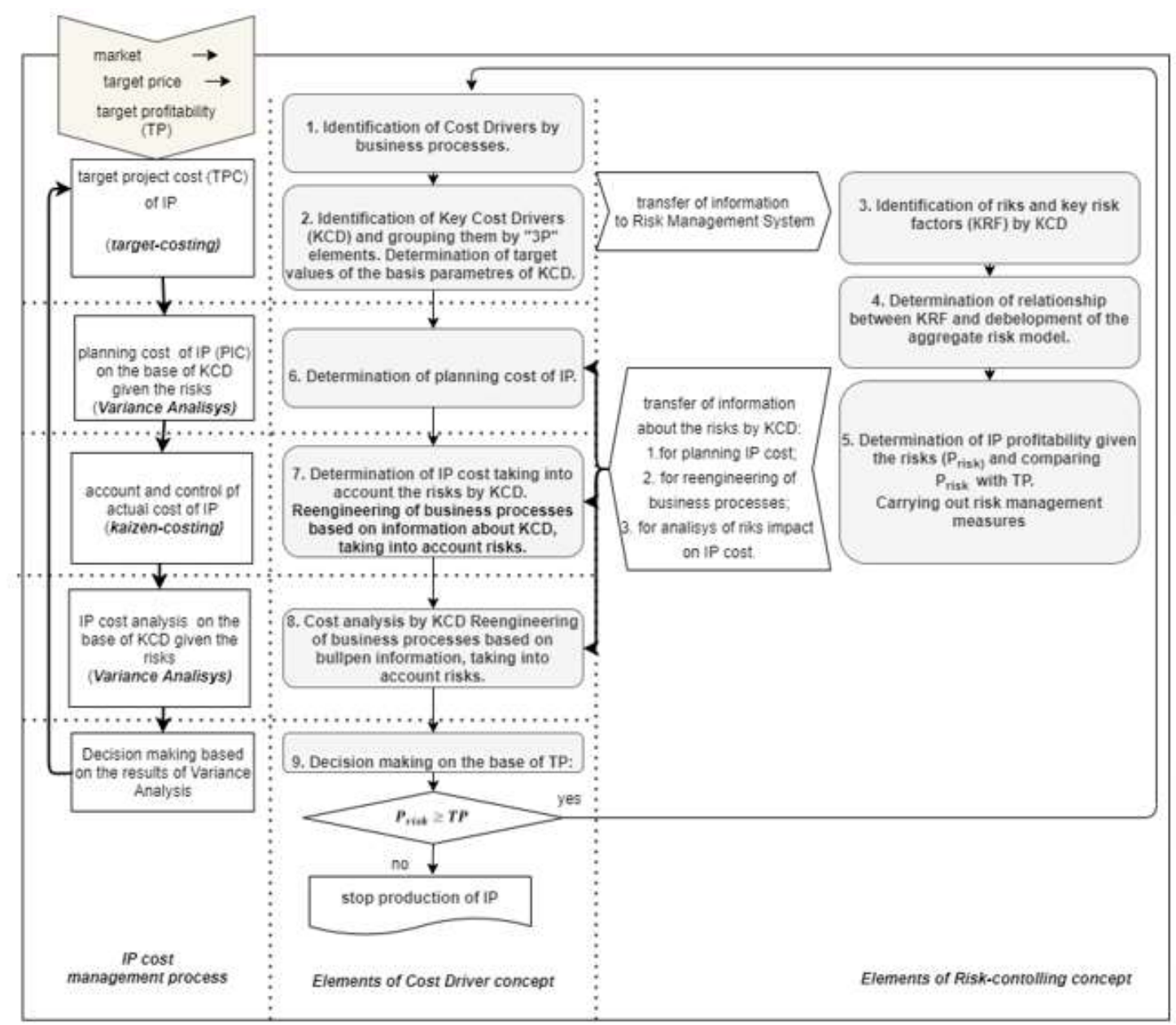

Figure 1 The mechanism for managing the costs of innovative products given the risks

In the second stage, the list of cost drivers that is broken down into business processes is used to identify the KCD, which are further grouped based on three main elements that can be used to describe any process: product, process, and personnel (the "3Ps") (Cook and Mo, 2018). In order to select the KCD, it is suggested that value engineering, the CDA method, or an expert method is used to determine the meaningful cost drivers in the product value chain of a certain enterprise. After that, the KCD are chosen using the Pareto method, ABC-XYZ analysis, or an expert method. In order to exclude the multicollinearity of the KCD, a pair correlation test has to be conducted. The criterion for selecting the drivers is that the correlation value cannot exceed 0.8. As a rule, the number of KCD should not exceed 12-15 (Lionel et al., 1998). Then, the target values of the main parameters of the KCD that allow the achievement of the TC are determined for each " $3 \mathrm{P}$ " element. It is suggested that the main parameters of the KCD are determined by " $3 \mathrm{P}$ " elements, as presented in Table 1. In order to identify and account for the risks in cost management, the list of the KCD and their target parameters are submitted to the risk management system.

In the third stage of the mechanism, the risk management system identifies risks and risk factors for each KCD. This stage is implemented according to the FERMA standard, 
based on which external and internal key risk factors (KRF) are categorized as strategic, financial, operational, and hazardous.

Table 1 The main parameters of the KCD based on the " $3 \mathrm{P}$ " elements

\begin{tabular}{llll}
\hline $\begin{array}{c}\text { Business } \\
\text { process } \\
\text { elements }\end{array}$ & \multicolumn{1}{c}{ Product } & \multicolumn{1}{c}{ Process } & \multicolumn{1}{c}{ Personnel } \\
\hline & $\begin{array}{l}\text { Output structure, } \\
\text { production volume, } \\
\text { and the quality of } \\
\text { Element } \\
\text { parameters }\end{array}$ & $\begin{array}{l}\text { Digitalization and } \\
\text { automation level of the } \\
\text { factory, high technology use, } \\
\text { and material resources }\end{array}$ & $\begin{array}{l}\text { Level of personnel } \\
\text { organization and } \\
\text { management, level of labor } \\
\text { intensity, and labor } \\
\text { resources }\end{array}$ \\
\hline
\end{tabular}

This procedure uses risk management tools, such as value chain analysis, SWOT analysis, an Ishikawa diagram, a fault tree, and an event tree.

In the fourth stage, the interplay between the KRF is determined, and an aggregate risk model is built. The probability approach can be used for that where: (1) the event probability distribution function and the event correlation coefficients are determined for each KRF, either according to the results of the projects that were implemented previously or using an expert method; and (2) the risk probability is assessed either through building a Bayesian network that connects the events, or through adding the probabilities given the correlations (Grishunin et al., 2020). For projects with a high degree of uncertainty, more complex models can be used for building models, such as: (1) applications of the fuzzy set theory; (2) applications of the evidence-based theory; and (3) artificial intelligence methods and neural networks (Grishunin et al., 2020).

Then, in the fifth stage, simulation modeling tools are used to determine the profitability index of the IP given the risks. If the profitability index is lower than the target profitability, the project is considered to be inefficient in terms of risk exposure, and some measures are taken to increase its efficiency: actions aimed at risk management are planned, and the profitability index is assessed for the second time. The risk management system forms risk projections for the KCD and transfers them to the cost management system. In order to make the information more illustrative, we recommend using combined 3D matrixes of risk consequence and risk probability for the KCD. The information about the risks revealed at the planning stage is used to determine the planned costs of the IP.

The information about the current risks identified in the course of the production process is used to reengineer business processes, while that regarding the risks revealed in the course of the entire production cycle is used to analyze the self-costs of the IP (Minakov et al., 2020).

During the sixth stage of the mechanism, we determine the planned costs of the IP given the expected risks based on the KCD. For this, it is recommended to use variance analysis (VA). The essence of this method is in identifying the change in the planned costs from the target ones due to the effect of the expected risks at the level of the KCD. The advantage of VA is the possibility of assessing the impact of each factor on the change in the costs. First, it is necessary to calculate the main parameters for each KCD given the risks using a general Equation 1:

$$
F_{\text {risk }}=F_{p l} \pm \Delta F_{\text {risk }} \times P_{\text {risk }} / 100
$$

where $F_{\text {risk }}$ is the value of the main parameter of the KCD given the risk; $F_{p l}$ is the value of the main parameter of the KCD corresponding to the target cost; $\Delta F_{\text {risk }}$ is the projected deviation in the main parameter of the KCD caused by the risk; and Prisk is the projected probability of the r-th risk occurrence, \%. 
Then, VA of the cost is performed for the main parameter of each element of the "innovations" business process:

VA of the cost for the "product" element:

"Output structure" parameter is $\Delta \mathrm{C}_{s t r_{j}}$ :

$$
\Delta \mathrm{C}_{s t r_{j}}=\left(C_{V C_{j}}^{s t r}-C_{V C_{j}}^{p l}\right) \times Q_{j}^{p l}
$$

where $\Delta \mathrm{C}_{s t r}$ is the change in the cost of the IP caused by the change in the output structure of the j-th type of IP; $C_{V C_{j}}^{s t r}$ is the variable costs given the risk for the j-th IP based on the KCD for the "output structure" parameter; $C_{V C_{j}}^{p l}$ is the variable costs, excluding the risk for the jth IP based on the KCD; and $Q_{j}^{p l}$ is the planned output of the j-th IP.

"Output structure" parameter (the fixed costs) is $\Delta C_{Q_{j}}$ :

$$
\Delta C_{Q_{j}}=C_{F C_{j}}^{Q}-C_{F C_{j}}^{p l}
$$

where $\Delta C_{Q_{j}}$ is the change in the costs of the IP due to the change in the output of the j-th IP; $C_{F C_{j}}^{Q}$ is the fixed costs of the j-th IP given the risk based on the KCD according to the "output" parameter; and $C_{F C_{j}}^{p l}$ is the fixed costs of the j-th IP excluding the risk based on the KCD.

"Product quality" parameter is $\Delta \mathrm{C}_{\text {quality }_{j}}$ :

$$
\Delta \mathrm{C}_{\text {quality }_{j}}=\left(C_{V C_{j}}^{\text {quality }}-C_{V C_{j}}^{p l}\right)+\left(C_{F C_{j}}^{\text {quality }}-C_{F C_{j}}^{p l}\right)
$$

where $\Delta \mathrm{C}_{\text {quality }_{j}}$ is the change in the costs of the IP due to the change in the quality of the IP; $C_{V C_{j}}^{q u a l i t y}$ is the variable costs of the j-th IP given the risk based on the KCD for the "product quality" parameter; $C_{V C_{j}}^{p l}$ is the variable costs of the $\mathrm{j}$-th IP excluding the risk based on the KCD; $Q_{j}^{p l}$ is the planned output of the j-th IP; $C_{F C}^{q u a l i t y}$ is the fixed costs of the j-th IP given the risk based on the KCD for the "product quality" parameter; and $C_{F C}^{p l}$ is the fixed costs of the j-th IP excluding the risk based on the KCD.

Total: cost deviation based on the KCD of the j-th IP for the "product" element is $\Delta C_{\text {product }_{j}}$ :

$$
\Delta C_{\text {product }_{j}}=\Delta \mathrm{C}_{s t r_{j}}+\Delta C_{Q_{j}}+\Delta \mathrm{C}_{\text {quality }_{j}}
$$

VA of the cost for the "process" element:

"The level of digitalization and automation" parameter is $\Delta C_{d i g_{j}}$ :

$$
\Delta C_{d i g_{j}}=\left(C_{V C_{j}}^{d i g}-C_{V C_{j}}^{p l}\right) \times Q_{j_{\text {to end }}}+\left(C_{F C_{j}}^{\text {dig }}-C_{F C_{j}}^{p l}\right)
$$

where $\Delta C_{d i g_{j}}$ is the change in the costs of the $\mathrm{j}$-th IP caused by a different level of digitalization and automation of production; $C_{V C_{j}}^{d i g}$ is the variable costs of the $\mathrm{j}$-th IP given the risk based on the KCD for the "level of digitalization" parameter; $C_{V C_{j}}^{p l}$ is the variable costs of the j-th IP excluding the risk based on the KCD; $Q_{j}$ to end is the output of the j-th IP from the moment of the risk occurrence based on the KCD; $C_{F C_{j}}^{d i g}$ is the fixed costs of the j-th IP given the risk based the KCD for the "level of digitalization" parameter; and $C_{F C_{j}}^{p l}$ is the fixed costs of the j-th IP excluding the risk based on the KCD.

"The use of material resources (raw and other materials, fuel, energy)" parameter: 
- changes connected with the consumption rates of material resources are $\Delta C_{\text {mat norm }}$ :

$$
\Delta C_{\text {mat norm }}=\left[\sum_{h=1}^{H}\left(N_{h_{\text {new }}}-N_{h_{p l}}\right) \times P r_{h}^{p l}\right] \times Q_{\text {to end }_{j}}
$$

where $\Delta C_{\text {mat norm }}$ is the change in the costs of the IP caused by the change in the consumption rates of the material resources for the manufacturing of the j-th IP; $N_{h_{\text {new }}}$ is the consumption rate of the h-th material resource for the manufacturing of a unit of the $\mathrm{j}$ th IP given the risk based on the "material resources" parameter of the KCD; $N_{h_{p l}}$ is the consumption rate of the h-th material resource excluding the risk based on the KCD; $P r_{h}^{p l}$ is the price of a unit of the h-th material resource excluding the risk based on the KCD; and $Q_{\text {to }_{\text {end }}}$ is the output of the j-th IP from the moment of risk occurrence based on the KCD.

- changes caused by the price of material resources are $\Delta C_{\text {mat }_{\text {price }}}$ :

$$
\Delta C_{\text {mat } \text { price }_{j}}=\left[\sum_{h-1}^{H}\left(P r_{h}^{n e w}-P r_{h}^{p l}\right) \times N_{h}\right] \times Q_{\text {to end }_{j}}
$$

where $\Delta C_{\text {mat }_{\text {price }}}$ is the change in the IP caused by the change in the price of the material resources for the manufacturing of the j-th IP; $\operatorname{Pr}_{h}^{\text {new }}$ is the price of a unit of the h-th material resource for the production of the j-th IP given the risk based on the KCD for the "material resources" parameter; $P r_{h}^{p l}$ is the price of the h-th material resource excluding the risk based on the KCD; $N_{h}$ is the consumption rate of the h-th material resource given the risk; and $Q_{\text {to end }_{j}}$ is the output of the j-th IP from the moment of the risk occurrence based on the KCD.

- changes caused by the use of new material resources are $\Delta C_{m_{m a t}}$ :

$$
\Delta C_{\text {mat }_{j}}=\left[\sum_{h-1}^{H}\left(P r_{h}^{n e w} \times N_{h}-P r_{h}^{p l} \times N_{h}^{p l}\right] \times Q_{j}^{p l}\right.
$$

where $\Delta C_{\text {mat }_{j}}$ is the change in the costs of the IP caused by the use of new material resources for manufacturing the j-th IP; $P r_{h}^{\text {new }}$ is the price of a unit of the h-th material resource for manufacturing the j-th IP for the "material resources" parameter; $P r_{h}^{p l}$ is the price of the h-th material resource with the target value of the "material resources" parameter; $N_{h}$ is the consumption rate of the h-th material resource given the risk; $N_{h}^{p l}$ is the consumption rate of the h-th material resource excluding the risk; and $Q_{j}^{p l}$ is the output of the j-th IP excluding the risk based on the KCD.

The total cost deviations based on the KCD of the j-th IP for the "process" element is $\Delta C_{\text {process }_{j}}$ :

$$
\Delta C_{\text {process }_{j}}=\Delta C_{\text {dig }_{j}}+\Delta C_{\text {mat norm }}+\Delta C_{\text {mat }_{\text {price }}}+\Delta C_{\text {mat }}
$$

VA of the cost for the "personnel" element.

"Organization of management and production" parameter is $\Delta C_{\text {man }_{j}}$ :

$$
\Delta C_{\text {man } j}=\left(C_{V C_{j}}^{\text {man }}-C_{V C_{j}}^{p l}\right) \times Q_{\text {to end }_{j}}+\left(C_{F C_{j}}^{\text {man }}-C_{F C_{j}}^{p l}\right)
$$

where $\Delta C_{\text {man } j}$ is the change in the costs of the $\mathrm{j}$-th IP caused by the change in the management and production organization; $C_{V C_{j}}^{\operatorname{man}}$ is the variable costs of the $\mathrm{j}$-th IP given the risk based on the KCD for the "management and production organization" parameter; $C_{V C_{j}}^{p l}$ is the variable costs of the j-th IP excluding the risk based on the KCD; $Q_{j}$ to end is the output of the j-th IP from the moment of the risk occurrence based on the KCD; $C_{F C_{j}}^{m a n}$ is the fixed costs of the j-th IP given the risk based on the KCD for the "management and production 
organization" parameter; and $C_{F C_{j}}^{p l}$ is the fixed costs of the j-th IP excluding the risk based on the KCD.

"The labor intensity of manufacturing the IP" parameter is $\Delta C_{\text {lab.int.j }}$ :

$$
\Delta C_{\text {lab.int.j }}=\left[\sum_{l=1}^{L}\left(L P_{l_{\text {new }}}-L P_{l_{p l}}\right) \times L R_{l}^{p l}\right] \times Q_{\text {to end }_{j}}
$$

where $\Delta C_{\text {lab.int. }}$ is the change in the cost of the j-th IP caused by the change in labor intensity; $L P_{l_{\text {new }}}$ is the labor intensity of manufacturing a unit of the $\mathrm{j}$-th IP in the I-th division given the risk based on the "labor intensity" parameter of the KCD; $L P_{l_{p l}}$ is the labor intensity of manufacturing the j-th IP in the I-th division excluding the risk based on the KCD; and $Q_{\text {to end }}$ is the output of the j-th IP from the moment of the risk occurrence based on the KCD.

"Labor rate" parameter is $\Delta C_{\text {labor rate }_{j}}$ :

$$
\Delta C_{\text {labor rate }_{j}}=\left[\sum_{l=1}^{L}\left(L R_{l}^{\text {new }}-L R_{l}^{p l}\right) \times L P_{l}\right] \times Q_{\text {to end }_{j}}
$$

where $\Delta C_{\text {labor rate }_{j}}$ is the change in the costs of the $\mathrm{j}$-th IP caused by the change in the price of labor resources; $L R_{l}^{\text {new }}$ is the cost of a unit of work time of the I-th division involved in the manufacturing of the j-th IP given the risk based on the KCD for the "labor costs" parameter; $L R_{l}^{p l}$ is the price of a unit of work time of the I-th division involved in manufacturing the j-th IP excluding the risk based on the KCD; $L P_{l}$ is the consumption rate of the h-th material resource given the risk; and $Q_{\text {to end }}$ is the output of the $\mathrm{j}$-th IP from the moment of the risk occurrence based on the KCD.

The total costs based on the KCD of the j-th IP for the "personnel" element are $\Delta C_{\text {labor }}$ :

$$
\Delta C_{\text {labor }_{j}}=\Delta C_{\text {man }_{j}}+\Delta C_{\text {lab.int.j }}+\Delta C_{\text {labor rate }_{j}}
$$

Based on the obtained values of cost deviations for the main parameters of the KCD according to the " $3 \mathrm{P}$ " elements, we find the total deviation from the target cost of the planned cost of the j-th IP given the risk:

$$
\Delta \mathrm{C}_{j}=\Delta C_{\text {product }_{j}}+\Delta C_{\text {process }_{j}}+\Delta C_{\text {labor }_{j}}
$$

In the seventh stage of the mechanism, the information about the current risks identified at the production stage is used to find ways to reduce the costs of the IP and bring them in line with the target level based on the reengineering of the business process with the use of the kaizen-costing system.

In the eighth stage, the information about the risks identified during the entire production cycle is used for a VA of the costs of the IP, and the impact made by each driver on the cost level is determined.

In the ninth stage, a decision is made based on the target profitability level: (1) if after the risks are managed the desired level of the target profitability of the IP is achieved, the decision is made to continue manufacturing the IP; but (2) if the target profitability cannot be reached, the decision is made to stop producing the IP for the current project. In order to reach the target profitability of the IP, the mechanism that monitors the achieved target values of the costs of the IP must be repeated continually throughout the entire cycle.

Today, the matter of accounting for risks in the cost management of IP has not been studied sufficiently (Minakov et al., 2020). As a rule, the existing scientific research suggests using a scenario method (Yin et al., 2013). Such an approach to the cost management of IP is neither efficient nor flexible since it is constrained by the number of scenarios (realistic, 
pessimistic, and optimistic) and does not consider the constantly changing environment (Banker et al., 2018).

The mechanism developed in this study for managing the costs of IP given the risks is based on using the up-to-date methods of target-costing, kaizen-costing, VA, and CDA, as well as the concepts of cost drivers and risk controlling, which ensure an inextricable connection between the costs, risks, and target profitability of IP. In addition, using a combination of target-costing/kaizen-costing methods, VA, and CDA gives the following advantages in comparison with the target-costing/kaizen-costing methods that are used today (Ahn et al., 2018; Banker et al., 2018; Wang et al., 2020): (1) accounting for the risks in cost management related to the interaction of an industrial enterprise with the turbulent external environment; (2) monitoring the execution of the target values of costs in order to achieve the target profitability of IP; and (3) increasing the adaptability, flexibility, and stability of cost management, which helps to increase the efficiency of an enterprise operating in the age of the digital economy. It should be noted that using the proposed mechanism for managing the costs of IP given the risks implies a high level of digitalization of the enterprise and the application of technologies, such as big data and cloud computing, which ensure the precision and reliability of the generated computations.

\section{Conclusions}

This paper suggests a mechanism for managing the costs of IP of an industrial enterprise, which: (1) considers the high level of volatility of the external environment common to the digital economy and the effects exerted by risks on cost management; (2) can be used for controlling the level of target costs and introducing corrections made to the costs in due time according to the changing external and internal conditions so that the target profitability can be ensured; and (3) is based on using up-to-date and high-precision tools and methods for assessing risks and their effects on the costs and profitability of the IP. The above advantages aim to increase the responsiveness and flexibility of the entire process of the cost management of IP, which ensures the competitiveness of such products.

Further research should first be about developing tools for introducing this mechanism into the corporate system of enterprise management. Second, it should be about creating tools and methods to be used with the mechanism that target a subsequent increase in the efficiency of the cost management system and, in particular: (1) the selection of the KCD of IP; and (2) the improvement of tools for analyzing risk factors related to KCD.

\section{Acknowledgements}

The research is partially funded by the Ministry of Science and Higher Education of the Russian Federation under the strategic academic leadership 'Priority 2030' program (Agreement 075-15-2021-1333 dated 30.09.2021).

\section{References}

Ahn, H., Clermont, M., Schwetschke, S., 2018. Research on Target Costing: Past, Present and Future. Management Review Quarterly, Volume 68(3), pp. 321-354

Banker, R.D., Byzalov, D., Fang, S., Liang, Y., 2018. Cost Management Research. Journal of Management Accounting Research, Volume 30(3), pp. 187-209

Bencsik, A., 2020. Challenges of Management in the Digital Economy. International Journal of Technology, Volume 11(6), pp. 1275-1285

Berawi, M.A., 2020. Managing Nature 5.0: The Role of Digital Technologies in the Circular Economy. International Journal of Technology, Volume 11(4), pp. 652-655 
Bhimani, A., 2020. Digital Data and Management Accounting: Why We Need to Rethink Research Methods. Journal of Management Control, Volume 31(1-2), pp. 9-23

Cook, M., Mo, J., 2018. Investigating into the Risks of Forming Alliance. In: Transdisciplinary Engineering Methods for Social Innovation of Industry 4.0, pp. 1135-1144

Daneci-Patrau, D., Coca, C.E., 2017. Methodological Considerations on the Process of Determining the Target Cost. Economics, Management \& Financial Markets, Volume 12(2), pp. 122-130

Donelan, J.G., Kaplan, E.A., 1998. Value Chain Analysis: A Strategic Approach to Cost Management. Journal of Cost Management, Volume 12(2), pp. 7-15

Grishunin, S., Suloeva, S., Nekrasova, T., Burova, E., 2020. Development of Risk Controlling Mechanism and Tools for Agile Projects in Telecommunications. In: Internet of Things, Smart Spaces, and Next Generation Networks and Systems: NEW2AN 2020, ruSMART 2020. Lecture Notes in Computer Science, Volume 12526.2020. Springer, Cham

Lionel, B.C., Khaled, El Emam, Bomarius, F., 1998. COBRA: A Hybrid Method for Software Cost Estimation, Benchmarking, and Risk Assessment. In: Proceedings of the $20^{\text {th }}$ International Conference on Software Engineering

Matsuoka, K., 2018. Variance Analysis in Fixed Revenue Accounting. Fixed Revenue Accounting: A New Management Accounting Framework, Volume 15, pp. 69-84

Minakov, V.F., Lobanov, O.S., Dyatlov, S.A., 2020. Three-Dimensional Trends Superposition in Digital Innovation Life Cycle Model. International Journal of Technology. Volume 11(6), pp. 1201-1121

Mizikovskii, I.E., 2020. Management Accounting of Expenses for Storage of Material Resources in the Conditions of Digital Transformation of the Industrial Enterprise. Accounting. Analysis. Auditing, Volume 7(3), pp. 56-63

Olszewska, K., 2019. Cost Management with Budgeting and Kaizen Costing. World Scientific News, Volume 133, pp. 171-190

Porter, M., 2005. Competitive Advantage: How to Achieve a High Result and Ensure Its Sustainability. Alpina Business Book, p. 246

Samimi, A., 2020. Risk Management in Information Technology. Progress in Chemical and Biochemical Research, pp. 130-134

Shank, J.K., Govindarajan, V., 1993. Strategic Cost Management: The New Tool for Competitive Advantage. Free Press, New York

$\mathrm{Su}, \mathrm{X} ., \mathrm{Wu}, \mathrm{S} ., 2019$. Innovation of Enterprise Cost Management Under Internet Plus Era. In: 2019 International Conference on Social Science and Education: ICSSAE 2019, pp. 611

Wang, C., Wang, F., He, S., 2020. Conceptualization on the Cost Management Model of Enterprise Supply Chain Under the Background of Big Data. In: Proceedings of the 2020 $\left(3^{\text {rd }}\right)$ International Conference on Computers in Management and Business (ICCMB 2020). Association for Computing Machinery, New York, NY, USA, pp. 19-24

Yin, Y., Lam, J.S.L., Tan, L.H.I., 2013. Integrated Cost and Risk Management Model for Improving Supply Chain Resilience. International Journal of Logistics Management, Volume 14, pp. 114-126 